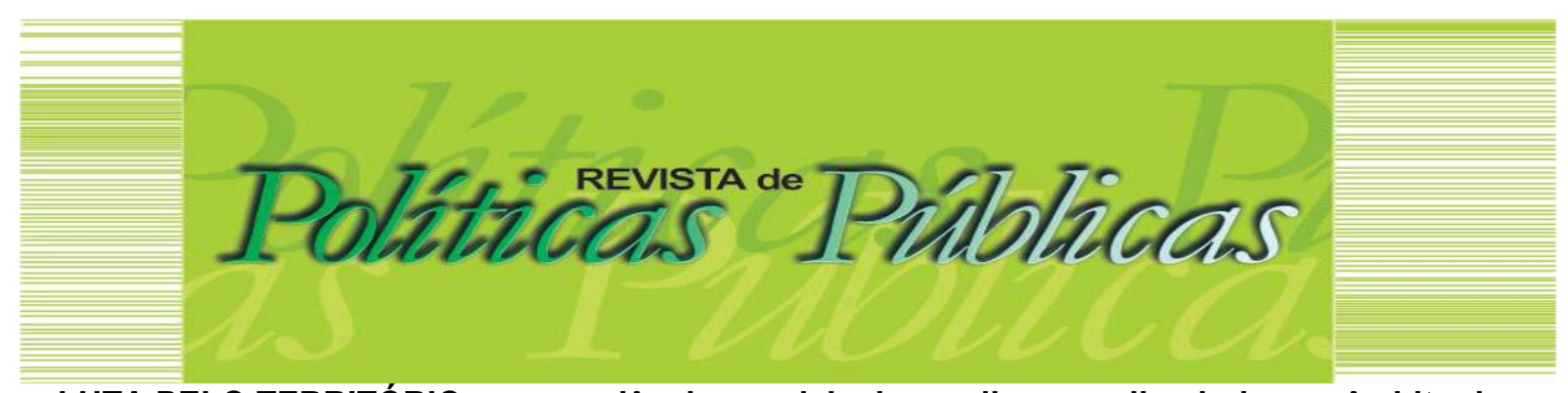

\title{
LUTA PELO TERRITÓRIO: as experiências sociais das mulheres quilombolas no âmbito das políticas públicas
}

\author{
Joana das Flores Duarte 1 \\ Patrícia Krieger Grossi ${ }^{2}$ \\ Eliane Moreira de Almeida ${ }^{3}$
}

\section{Resumo}

Este artigo é resultado de uma pesquisa iniciada em 2015 e ainda em andamento, cujo objetivo foi compreender as experiências sociais de mulheres quilombolas no âmbito das políticas públicas, considerando as interseccionalidades de gênero, raça/etnia, classe social e geração no Rio Grande do Sul. Quanto à natureza da pesquisa, ela se caracteriza como qualitativa e exploratória. Das técnicas utilizadas, optou-se por coleta de dados e entrevistas semiestruturadas. Os dados foram submetidos à análise de conteúdo sob a perspectiva de Bardin. Os resultados evidenciam que essas mulheres vivenciam violações no acesso às políticas públicas devido ao racismo estrutural, à especulação imobiliária e latifundiária, e as narrativas revelam os desafios no sentido de Ser quilombola em face da negação permanente do acesso aos direitos de cidadania, bem como às lutas e resistências dessas comunidades.

Palavras-chave: Territórios. Quilombos. Mulheres. Estado. Políticas Públicas.

\section{FIGHT FOR TERRITORY: the social experiences of quilombola women in the context of public policies}

\begin{abstract}
This article is the result of a research that began in 2015 and is currently underway, whose objective was to understand the social experiences of quilombola women in the context of public policies, considering the intersectionalities of gender, race/ethnicity, social class and generation in Rio Grande do Sul. This is a qualitative and exploratory research. The techniques used were data collection and semi-structured interviews. The data were subjected to content analysis from the perspective of Bardin. Results show that these women experience violations in accessing public policies due to structural racism, and to real estate and land exploitation, and the narratives reveal the challenges in the sense of being a quilombola in the face of the permanent denial of access to citizenship rights, as well as the struggles and resistance of these communities.
\end{abstract}

Keywords: Territories. Quilombos. Women. State. Public policies.

Artigo recebido em: 02/07/2021 Aprovado em: 20/11/2021 DOI: http://dx.doi.org/10.18764/2178-2865.v25n2p618-635

\footnotetext{
${ }^{1}$ Assistente Social. Doutora em Serviço Social. Professora adjunta no Curso de Serviço Social da Universidade Federal de São Paulo (UNIFESP), no Campus da Baixada Santista. Integrante do GT e da Red de Posgrados en Ciencias Sociales CLACSO e do NETeG - Núcleo de Estudos do Trabalho e Gênero. E-mail: jf.duarte@unifesp.br

${ }^{2}$ Assistente Social. Doutora em Serviço Social. Professora Adjunta do Curso de Serviço Social da Escola de Humanidades e do corpo permanente do Programa de Pós- graduação em Serviço Social da Pontifícia Universidade Católica do Rio Grande do Sul (PUCRS) e do Programa de Pós-graduação em Geriatria e Gerontologia do Instituto de Geriatria e Gerontologia. E-mail: pkgrossi@pucrs.br

${ }^{3}$ Assistente Social. Doutoranda em Serviço Social na Pontifícia Universidade Católica do Rio Grande do Sul (PUCRS). Email: eliane.almeida@acad.pucrs.br
} 


\section{INTRODUÇÃO}

O presente artigo é resultado de uma pesquisa iniciada em 2015 e que se encontra em andamento, cujo objetivo geral foi 0 de compreender as experiências sociais das mulheres quilombolas no âmbito das políticas públicas, considerando as interseccionalidades de gênero, raça/etnia, classe social e geração no estado do Rio Grande do Sul.

Por experiência social, compreende-se "o necessário conhecimento do modo de vida, concreto, apreendido como o real vivido pelos sujeitos, apreendidos pelas expressões sobre suas crenças, valores, sentimentos e ainda pela apropriação de suas próprias experiências vivenciadas cotidianamente" (MARTINELLI, 1999, p. 23). Assim, dá-se o reconhecimento das particularidades e subjetividades das pessoas entrevistadas, ao mesmo tempo em que se tem o entendimento de coletividade que estas representam a partir de suas inserções grupais.

A pesquisa, de natureza qualitativa e exploratória, utilizou como técnicas de coleta de dados entrevistas semiestruturadas que têm sido realizadas nos quilombos; destacam-se, urbanos e rurais do estado do Rio Grande do Sul. Tais dados foram submetidos à análise de conteúdo sob a perspectiva de Bardin (1977), que prevê uma série de etapas para a sistematização e interpretação dos dados.

Neste artigo são apresentadas as experiências sociais de lideranças femininas quilombolas de distintas regiões do estado do Rio Grande do Sul. Além das lideranças femininas, temos também uma liderança masculina quilombola e o atual Presidente da Frente Quilombola do Rio Grande do Sul. Cabe destacar que neste artigo seus nomes são identificados, isso porque ao trabalharmos com as narrativas de lideranças, partimos da assertiva de que essas pessoas ocupam lugares/cargos que Ihes dão centralidade e visibilidade junto à sociedade. São, como narraram, lideranças que atuam politicamente e de forma ativa no estado do Rio Grande do Sul em defesa da exigibilidade territorial dos quilombos. A identificação de seus nomes foi autorizada por eles/as.

O grande feito desta pesquisa, sem dúvida, foi a possibilidade de contato direto com as mulheres quilombolas e poder ouvi-las num rito de oralidade. Esse que não só resgata, mas afirma a ancestralidade de suas vidas e histórias. Foi sentando-nos e ouvindo, como fazem entre os seus, que tivemos a oportunidade de realizar este trabalho. Desse modo, a pesquisa cumpre o seu papel teórico, científico, ético, político e também afetivo, porque faz a mediação com os/as sujeitos/as pela experiência que transcende o lugar de pesquisador/a.

Não é possível ingressar numa comunidade quilombola somente com as vestes da academia, com seus termos e roteiros de pesquisa. Exige-se de quem ingressa uma "entrega" à 
sociabilidade, ao ambiente, ao tempo e espacialidade que figuram uma outra rotina - que vai desde as refeições coletivas, até se sentar em roda para falar sobre os causos. No dizer da historiadora, migrante, nordestina, poeta, ativista, professora, pesquisadora e intelectual Beatriz Nascimento (RATTS, 2006, p. 53), a utilização do termo quilombo:

[...] passa ter uma conotação basicamente ideológica, basicamente doutrinária, no sentido de agregação, no sentido de comunidade, no sentido de luta como se reconhecendo homem, como se reconhecendo pessoa que realmente deve lutar por melhores condições de vida, porque merece essas melhores condições de vida desde o momento em que faz parte dessa sociedade.

Dito isso, o presente artigo tem como desafio trazer aos leitores/as essas experiências que perpassam as violações no acesso às políticas públicas, o racismo estrutural e institucional, a especulação imobiliária e latifundiária, os desafios no sentido de Ser quilombola em face da destituição e negação permanente do acesso aos direitos de cidadania às comunidades remanescentes de quilombos, tanto do campo quanto da zona urbana. Esse é outro elemento de suma importância, as dissenções e aproximações entre quilombos urbanos e rurais e como, no tempo presente, ambos lutam pelo direito à terra, ao espaço e ao tempo, em face da barbárie do capital.

Em relação à sua estrutura, o artigo está dividido em quatro partes: a primeira é a presente introdução; a segunda parte aborda "Território e identidade quilombola: uma luta pela liberdade"; e na terceira versa-se sobre as "Narrativas de mulheres quilombolas: afetos, lutas e resistências" - por meio dessas narrativas é possível compreender a importância da mulher quilombola na esfera política e na tomada de decisões; elas perpassam o campo dos afetos, do acolhimento e da sensibilidade, mas sem se descuidar de suas raízes, marcadas por opressões e resistências, o que possibilita às mulheres do quilombo, no tempo presente, um rememorar com conteúdo crítico e reivindicatório no âmbito das políticas públicas. E, por fim, têm-se as considerações finais.

\section{TERRITÓRIO E IDENTIDADE QUILOMBOLA: uma luta pela liberdade}

\footnotetext{
"A luta quilombola é uma luta abolicionista [...], ela é uma luta pela liberdade, território é liberdade, território é a reconstrução da África que nos foi retirada, é o nosso modo de viver, de ser, de criar filhos e filhas, netos e netas. Eu costumo olhar os oito territórios quilombolas aqui como áreas livres, territórios livres, livres de fato, não no discurso. Livres para que se exerça efetivamente o seu ser." (ONIR ARAÚJO, Presidente da Frente Quilombola do Rio Grande do Sul, 07/06/2021).
}

O reconhecimento da terra, da territorialidade quilombola é o principal direito pelo qual lutam as comunidades remanescentes de quilombos no Brasil, pois é este que lhes garante, pela via do 
Estado, 0 acesso aos demais direitos e políticas públicas. Tal direito foi alçado por meio do artigo 68, da seção de Disposições Constitucionais Transitórias da Constituição Federal em 1988, que determina "Aos remanescentes das comunidades dos quilombos que estejam ocupando suas terras é reconhecida a propriedade definitiva, devendo o Estado emitir-Ihes os títulos respectivos". Cabe ressaltar que tal marco legal se deu cem anos após a abolição da escravidão e, ainda assim, encontrase longe da efetivação.

O que acontece é que o processo para a emissão de tais títulos é demasiadamente lento e burocrático, uma vez que se dá através de uma série de etapas, sujeitas a interposições e recursos. Existem comunidades quilombolas que estão com o processo de titulação aberto há mais de 20 anos e ainda não obtiveram êxito (BRASIL, 2021). Em consulta realizada em junho de 2021 no site da Fundação Cultural Palmaresi, constava o número de 2.809 comunidades quilombolas certificadas5; destas, apenas 33 possuíam a titulação, isso é, o reconhecimento definitivo e legal da posse de seus territórios (BRASIL, 2021).

No que concerne ao estado do Rio Grande do Sul, existem apenas duas comunidades tituladas: Família Silva (Porto Alegre) e Novo Horizonte/Rincão dos Caixões (Jacuizinho e Tunas), e outras duas comunidades - Rincão dos Martinianos (Restinga Seca) e Casca (Mostardas) - possuem titulação parcial, em um total de 134 comunidades já certificadas (BRASIL, 2021).

Dessas 134 comunidades, sete delas se encontram no município de Porto Alegre, a capital do estado, como pode ser visto no Quadro 1, e serão tratadas enquanto quilombos urbanosii.

Quadro 1 - Comunidades quilombolas certificadas em Porto Alegre

\begin{tabular}{|c|c|c|c|}
\hline COMUNIDADE & $\begin{array}{c}\text { DATA DA } \\
\text { ABERTURA }\end{array}$ & $\begin{array}{c}\text { ETAPA ATUAL } \\
\text { PROCESSO }\end{array}$ & $\begin{array}{c}\text { ETAPA DO PROCESSO } \\
\text { DE TITULAÇÃO }\end{array}$ \\
\hline FAMÍLIA SILVA & $11 / 06 / 2003$ & CERTIFICADA & TITULADA FCP \\
\hline AREAL LUIZ GUARANHA & $28 / 05 / 2004$ & CERTIFICADA & PORTARIA NO DOU \\
\hline ALPES & $16 / 12 / 2004$ & CERTIFICADA & DECRETO NO DOU \\
\hline FAMÍLIA FIDELIX & $25 / 01 / 2007$ & CERTIFICADA & RTID \\
\hline FAMÍLIA MACHADO & $03 / 04 / 2014$ & CERTIFICADA & \\
\hline FAMILIA FLORES & $17 / 04 / 2015$ & CERTIFICADA & \\
\hline FAMÍLIA LEMOS & $28 / 08 / 2018$ & CERTIFICADA & \\
\hline
\end{tabular}

Fonte: Adaptado de Fundação Cultural Palmares (BRASIL, 2021).

Além das sete comunidades certificadas pela Fundação Cultural Palmares, Porto Alegre também conta com o Quilombo Família de Ouro, ainda não certificado, mas autorreconhecido, o que, na fala de sua liderança, é o elemento primordial de uma comunidade quilombola. 
Nós não temos uma titulação da Palmares, mas nós temos o reconhecimento a mais de dois anos [...] porque para nós 0 que vale não é o papel que vem de alguém nos dizendo que nós somos povo quilombola, ninguém vai nos dizer isso, essa autodeclaração vem de dentro de nós, vem do nosso coração, vem das nossas lutas e isso para mim é o que é importante. (MÃE PATTY DE OXUM, Liderança do Quilombo Família de Ouro, Porto Alegre, 07/06/2021).

Assim, considera-se a existência de sete comunidades quilombolas certificadas no município de Porto Alegre, e onze autodeclaradas, pois esse é o número informado pela população quilombola, como veremos em seguida. A fala da liderança demonstra a importância da autodeclaração, do autorreconhecimento da identidade quilombola. Segundo 0 artigo $2^{0}$ do Decreto $n^{0}$ 4.887iii, de 20 de novembro de 2003, são considerados remanescentes das comunidades dos quilombos: "[...] os grupos étnico-raciais, segundo critérios de auto-atribuição, com trajetória histórica própria, dotados de relações territoriais específicas, com presunção de ancestralidade negra relacionada com a resistência à opressão histórica sofrida" (BRASIL, 2003).

Outro quilombo que busca reconhecimento em Porto Alegreiv em 2021 é o Quilombo Kédi, que se autoidentifica como comunidade remanescente de quilombo e diz possuir relação de pertencimento e territorialidade associada ao primeiro quilombo urbano de Porto Alegre, o Quilombo Família Silva. Essa comunidade que se autodeclara quilombola está sendo ameaçada de remoção de seu território, localizado no Bairro Três Figueiras, considerado um bairro de classe média alta, sendo um dos metros quadrados mais caros de Porto Alegre. Ainda existem mais dois quilombos em Porto Alegre que estão buscando reconhecimento.

Ao longo do desenvolvimento da pesquisa, constatou-se que entre o que pressupõe 0 decreto e a realidade vivida pelas comunidades há um conjunto de particularidades e subjetividades que interpela a identidade quilombola e que não pode ser simplesmente abarcado e compreendido em poucas linhas.

Em se tratando das relações territoriais, por exemplo, as comunidades de Porto Alegre compartilham uma trajetória comum em sua gênese, a saída de pessoas remanescentes de quilombos de regiões do interior do estado, devido ao processo de desterritorializaçãov , para a capital, culminando na ocorrência da reterritorialização - que "[...] guarda novos traços e trajetórias, muitas vezes divergentes da territorialidade estabelecida anteriormente, não significando apenas uma transferência de lugar: representa uma nova rede de relações e processos que desencadeiam nova codificação" (SOMMER, 2005, p. 37).

Esse é o caso da comunidade Família Fidélix, que, desterritorializada do município de Santana do Livramento, se reterritorializou em Porto Alegre, enfrentando uma série de desafios na reconstrução e desenvolvimento da comunidade (SILVA, 2015). 
Em uma das entrevistas realizadas com a liderança da comunidade, foi descrito que, no ano de 2006, houve uma ação da prefeitura da cidade que expulsou famílias de suas casas sob a justificativa de que o terreno no qual está localizada a comunidade pertence à própria prefeitura. Após mobilizações, algumas famílias puderam retornar; entretanto, tal fato fez com que o território da comunidade fosse circunscrito, o que alterou a dinâmica e as formas de organização da comunidade.

Situação semelhante foi vivenciada pela Família Lemos, que sofreu com tentativas de reintegração de posse por parte do Asilo Padre Cacique em 2018 e 2020. Essa é outra comunidade oriunda do interior, da cidade de Canguçu, que se viu forçada aos processos de desterritorialização e reterritorialização. Destarte, não pode ser considerado apenas o território atual no qual se encontram as comunidades, mas suas trajetórias históricas.

Desse modo, em relação aos quilombos urbanos de Porto Alegre, é válido ressaltar que seu cotidiano ainda é marcado pelas constantes tentativas de desterritorialização, fruto, majoritariamente, da especulação imobiliária, que, sob o discurso de desenvolvimento urbano, se utiliza de mecanismos que têm a intenção de afastar a população de seus territórios (COSTA, 2008). Ainda sobre territórios, aqui, concorda-se com a afirmativa de que:

O território não é apenas o conjunto dos sistemas naturais e de sistemas de coisas superpostas. 0 território tem que ser entendido como o território usado, não o território em si. 0 território usado é o chão mais a identidade. A identidade é o sentimento de pertencer àquilo que nos pertence. 0 território é o fundamento do trabalho, o lugar da residência, das trocas materiais e espirituais e do exercício da vida. (SANTOS, 1999, p. 8).

Assim, falar de territórios quilombolas não é falar do espaço geográfico em si, mas falar da identidade assumida por tais territórios a partir de suas e de seus ocupantes, das relações e organizações ali estabelecidas. É destacar a trajetória de luta e resistência desses grupos frente a uma realidade de incertezas, inseguranças e não efetivação de direitos constitucionais. Quanto à autoatribuição referida pelo decreto, isto é, declarar-se quilombola, é necessário reconhecer, conforme nos sinaliza a liderança quilombola Sandro Lemos, sua práxis insurgente, visto que, "Antes de um território quilombola, a gente tem que se sentir como quilombola" (06/07/2021).

O Brasil é um país que se forjou através do racismo e da discriminação étnica, o último país do continente americano a abolir a escravidão e que, mesmo hoje, mais de um século depois, carrega profundas marcas e desdobramentos desse processo histórico. O pano de fundo dessa história escravagista se conforma, na contemporaneidade, no racismo estrutural. Este, para Almeida (2018), representa uma sociedade que se organiza - individual e coletivamente - a partir do racismo enquanto um processo social. 
Sob esse aspecto, foi destacado por participantes da pesquisa que algumas pessoas das comunidades não se cadastravam enquanto quilombolas porque não queriam ser vistas enquanto pessoas negras. Essa negação da identidade é uma das formas de tentar evitar essa estrutura racista.

Em contrapartida, foram expressivas as falas e ações que propunham o reconhecimento $e$ a valorização da história, da cultura negra e do povo negro como forma de organização, luta e resistência dentro e fora das comunidades. Por isso, a autodeclaração, parte inicial no processo de titulação, é tão essencial.

"[...] faz pouco tempo que a gente se autodeclara como quilombola, mas já vem de berço, da essência mesmo [...] de ser pessoa coletiva. Eu acho que ser quilombola é essa afetividade, a luta constante, não desistir jamais, resistir a todas as lutas e dificuldades que acabam vindo junto com esse reconhecimento." (JANJA, Liderança feminina quilombola, Quilombo Alpes, Porto Alegre, 09/05/2018).

Essa coletividade que a participante traz quando define o que é Ser quilombola foi um fato imensamente percebido no desenvolvimento da pesquisa. Todas as decisões são tomadas em conjunto e através do diálogo nas associações. Nas tentativas de reintegração de posse e despejos, as comunidades se unem para a ocupação conjunta do território. No dizer de Sandro Lemos, liderança masculina no Quilombo Lemos "Os 8 quilombos são interligados, o que muda é só o CEP, a gente se considera, e somos irmãos, já vem da nossa ancestralidade" (07/06/21).

Nesse sentido, o próximo item traz ênfase ao protagonismo das mulheres quilombolas nessa luta por garantia e efetivação de direitos e políticas públicas, bem como a relação com a afirmação da identidade quilombola.

\section{AS EXPERIÊNCIAS SOCIAIS DAS MULHERES QUILOMBOLAS: afetos, lutas e resistências}

Ao falarmos que as narrativas das mulheres quilombolas são constituídas por afetos, lutas e resistências, destacamos que elas avançam do ponto de vista da luta política. Progridem porque desmistificam a romantização sobre o que conhecemos por afeto e por relações afetivas. Se tivemos no marco da história do nosso país a colonização e formas estruturadas de dominação entre povos, raças, gêneros e classes, o afeto foi um dos elementos capturados tanto para atender à lógica senhorial quanto para, mais tarde, ser associado ao poder de compra.

Para essas lideranças femininas, o afeto é a essência de Ser quilombola - identidade e pertencimento que não lhes são externos, pelo contrário. A referência aos/às antepassados/as se faz enquanto rememoramento diário da dimensão política, social, cultural, econômica, civil e afetiva em ser quilombola. Com elas, desbravamos a dimensão radical-ancestral dessa consciência, por darem ao 
afeto sentido social e histórico, ao mesmo tempo desvinculando-o das referências colonizadoras. Afeto, nesse sentido, é mais que 0 ato de expressar carinho e ouvir as dores das opressões, é um ato político que une e fortalece toda uma comunidade em torno de um objetivo comum: acessar direitos. Com isso, é formada uma ética fundada em princípios que provêm de todas e todos, resguardada a concepção de universalidade. Para a liderança feminina Janja:

\begin{abstract}
"Essa afetividade é a luta constante, não desistir jamais, resistir a todas as lutas e dificuldades que acabam vindo junto com esse reconhecimento. A gente sabe que tem direitos, mas é difícil a gente acessar, difícil a gente trazer para dentro da comunidade, para dar vida digna, formar cidadãos e melhoria para as nossas crianças aí. Sabemos que existe o Minha Casa, Minha Vida, e que muitas famílias aqui dentro poderiam acessar... não digo que bem instaladas, mas estão instaladas. Mas têm muitas que estão em péssimas condições de instalação, né, e que a gente sabe que tem recurso lá, e a gente faz toda uma luta, né, para estar trazendo essa melhoria, mas olha, é frustrante." (JANJA, liderança feminina quilombola, Quilombo Alpes, Porto Alegre, 09/05/2018).
\end{abstract}

Esse afeto é, portanto, revolucionário, porque se firma na perspectiva coletiva, em que a comunidade, por meio dele, estabelece também uma forma de linguagem, de interação e promoção da vida em conjunto. Para além disso, ele mostra os limites de uma sociedade fundada na desigualdade, e que, embora seja o quilombo uma expressão de resistência e ancestralidade, comunga na atualidade com a luta de classes, visto que essas lideranças e suas comunidades buscam a garantia e a positivação de direitos assegurados e conquistados na arena das contradições entre capital e trabalho. 0 afeto, aqui, desmistifica o que entendemos e estabelecemos sobre esse sentimento determinado pelas relações sociais na sociedade capitalista. Diante de todas as negações e violações de direitos, essas lideranças femininas quilombolas realizam uma espécie de "costura" entre os seus, buscando dessa forma manter o elo que não só os assegura enquanto povos remanescentes de quilombos, mas que, somando a isto, os distingue. Para Vanda, Ser quilombola é:

\footnotetext{
"Primeiramente ter a consciência que somos negros e que somos descendentes de africanos escravizados, não de escravos. Agora já sabemos que existe governo, que temos direitos! Isso é importante para que a gente possa tocar melhor nossa vida no quilombo. Ser quilombola é lutar sempre! Aprendi isso como a minha mãe, pela insistência dela em ficar aqui. Foi pela permanência dela aqui que nos tornamos quilombolas, somos remanescentes de quilombo." (VANDA, liderança quilombola feminina, Quilombo Rincão dos Fernandes, Uruguaiana, 21/04/2018).
}

O reconhecimento em Ser mulher quilombola, por exemplo, se faz por meio dessa mediação afetiva. Uma mulher quilombola se reconhece enquanto tal a partir do seu povo, da sua espacialidade, sociabilidade, ancestralidade, oralidade e rito de vivência. Ser mulher quilombola, para elas, é ser sujeita do presente compromissada com o passado, esse que é a afirmação de suas raízes, identidade e pertencimento. Nada disso ocorre por vias externas, embora narrem a participação central do movimento negro. Esse que, mesmo estando "fora" da espacialidade quilombola, é também parte 
dela no que diz respeito à luta política no tempo presente e memória ancestral. Conforme é possível ler nas narrativas das lideranças Ilza e Vanda, respectivamente:

"O movimento negro nos explicou o que era ser remanescente de quilombo, e que tínhamos o direito de regularizar as terras, e foi a partir daí que começou a luta. 0 pessoal do movimento negro nos ajudou muito, e a partir daí não foi preciso fazer usucapião. Esses fazendeiros de antigamente, os fazendeiros gostavam muito de mandar nas pessoas, então alguns conseguiram fazer usucapião, o restante não, então o movimento negro veio aqui e começou a conversar com nós dizendo que podíamos formar uma associação." (Ilza, liderança feminina quilombola, Quilombo Casca, Mostardas, 14/06/2018).

"A gente contou com a formação do movimento negro de Uruguaiana, que foi que nos ajudou a formar a nossa associação. $\mathrm{Na}$ época contamos com a professora Stael Soraya. Ela e vários outros membros vieram, assim como a Nádia Russi, a Márcia Barragan Goulart. Tivemos também um historiador. Todos eles e o movimento negro nessa época nos ajudaram no nosso estatuto e nos encaminharam, porque nós precisávamos de um advogado para que o pedido fosse feito. Eles nos deram essa mão." (Vanda, liderança quilombola feminina, Quilombo Rincão dos Fernandes, Uruguaiana, 21/04/2018).

Ao falarmos sobre os processos da colonização e escravização no Brasil, a liderança feminina quilombola Vera pontua que o denominado branqueamento foi (e segue sendo), na prática, uma estratégia da colonização para frear as lutas e resistências dos negros. Segundo ela não é possível falar em quilombo no presente sem revistar a história da escravidão.

\begin{abstract}
"Toda mulher negra na verdade ela tem seus saberes que ela traz das suas raízes. É que com o decorrer do tempo, o que é que aconteceu? A gente foi influenciada com o externo. Vamos dizer assim: a gente foi perdendo nossa cultura. Nos tiraram nossas bagagens, nossos ancestrais, nossa língua, nossa religiosidade, o nosso tudo.... No momento que tiraram, a gente perdeu. Tudo o que sabemos é pela oralidade dos mais velhos. Minha avó que morreu com cento e quatro anos nos contava em rodas de conversas sobre a história dos seus ancestrais. Tudo que ela passou para a gente na roda de conversa é o que temos. Ela dizia que faziam aquilo também com ela. Contava que faziam fogo de chão dentro de casa, dentro do quarto para aquecer a casa, no meio da fumaça eles sentavam para tomar um chá da própria horta que eles cultivavam... assim ela fez com a gente. Ela contou da formação dos quilombos, do lugar que ela nasceu, como que surgiu o quilombo e tudo mais. Então foi assim que eu fiquei sabendo da minha história, e logo depois, a gente começou a sair nos encontros do Movimento Negro e da Pastoral Afro." (Vera, liderança feminina quilombola, Quilombo Boqueirão, São Lourenço, 03/07/2018).
\end{abstract}

No que se refere às questões de sexo/gênero, as mulheres quilombolas avançam também na leitura antipatriarcal, ainda que não se autodeclarem feministas, visto que revelam, a partir dos efeitos da dominação patriarcal e do branqueamento eurocêntrico, a apropriação e feminilização da afetividade. Fica visível a partir de suas narrativas que as formas de negação desse afeto patriarcal capitalizado foram absolutamente distinguíveis entre países do centro e da periferia. Enquanto, nos países desenvolvidos, 0 afeto foi lido como uma condição imposta pelo sistema patriarcal e apropriada pelo capitalismo, nos países colonizados e dependentes, esse afeto ora foi negado, ora incorporado sob tutela da Casa Grande e Senzala (FREYRE, 2013) na figura da mãe preta. Para a liderança 
quilombola Vera, o processo de escravização precisa não só ser revisitado, mas compreendido à luz dos povos remanescentes.

\begin{abstract}
"Na verdade, não fomos escravos, nós fomos escravizados! Quem deve ter vergonha são os descendentes de quem nos escravizou, e não nós! Foram eles que trouxeram nossos ancestrais para trabalharem para eles, pois eles não tinham capacidade para isso. Uma mulher escravizada perdia um filho no mato para dar leite para o filho da sinhazinha. 0 quilombo deixa isso vivo. Então tudo isso são valores. Desde pequena eu tive a minha avó contando histórias, o meu pai e minha mãe, eles contando as histórias do que o povo negro sofria. Mas, também, falavam de tudo que se aprendia entre eles, o que um não sabia fazer ensinava para o outro. Eu vejo isso hoje aqui e dentro do Movimento Negro, do movimento social, esse que de fato foi pegar "o fio da meada" e desenrolar o novelo." (Vera, liderança feminina quilombola, Quilombo Boqueirão, São Lourenço, 03/07/2018).
\end{abstract}

As mulheres negras, pós-independência, seguiram desempenhando as mesmas atividades relativas ao trabalho doméstico, permaneceram como empregadas domésticas, no rito contraditório entre afeto e dominação. Diferentemente dos homens negros "livres", que ficaram sem trabalho e marginalizados pela política penal do Estado, a mulher negra teve um lugar associado ao cuidado. Nessa via, apropriaram-se do afeto e o privatizaram na dinâmica entre senhor e servo. Segundo a liderança quilombola Vera, até mesmo o trabalho doméstico só foi incorporado na agenda das políticas públicas quando a mulher branca passou a ocupá-lo de forma remunerada.

"Nunca ninguém se preocupou em fazer uma política pública para a doméstica negra, nunca... Hoje todo mundo cobra os direitos da doméstica porque a mulher branca entrou nesse mercado de trabalho. Enquanto eram só as negras, ninguém falava, ninguém dava direito. As negras podiam perder os cascos das unhas trabalhando, esfregando o chão da sinhazinha, que as negras não tinham direito. Hoje então é isso aí, os negros continuam sem 0 direito, eles pensam que a gente tem o direito até demais, aí chegam a dizer: 'Por que cotas para negros?' 'Agora tão dando casa?' 'Pros brancos não tão dando casa, mas para os negros, sim'. Olha, eu digo: porque os negros estão todos lá embaixo. Tem os brancos pobres também, que não podem fazer faculdade e que não tem casa, que não tem saneamento básico na casa, que não tem água, que não tem luz... só que se tu olhas para 0 geral, tu só vai ver branco tendo as coisas." (Vera, liderança feminina quilombola, Quilombo Boqueirão, São Lourenço, 03/07/2018).

Da sociedade feudal à capitalista, o estabelecimento do afeto como expressão do privado empobreceu a experiência coletiva desse sentimento. Todavia, essa refutação não se deu em condição de igualdade entre todas as mulheres. Para as mulheres pobres e pretas, manter-se na casa grande não foi uma escolha, mas sim uma forma de sobrevivência - situação que perpassa séculos na vida das mulheres e dos homens quilombolas, sobretudo nos quilombos urbanos, afetados não só pela especulação imobiliária e segregação socioespacial, mas também pela dinâmica capitalista de exploração da força de trabalho dos segmentos mais pobres. Não por acaso, os quilombos urbanos são, em muitas situações, vistos como vilas/favelas, isso porque ou estão em áreas em que houve um 
aumento da periferia, ou porque estão em áreas nobres da cidade, em que suas casas e condições de moradia destoam do ponto de vista econômico e social dos condomínios privados.

\begin{abstract}
"O pessoal das imobiliárias está sempre aí dizendo: 'Ah, que vista!'. Por isso é que a gente tem muita dificuldade, porque eles (governantes) não querem estruturar nós. 'Para quê que vamos ajeitar lá, botar segurança, botar iluminação pública lá, se não é prédio, não é elite?!'. Olha, o jeito que está a cidade, o jeito que está as periferias, as vilas, tudo se matando, por quê? Porque não têm oportunidades, não tem emprego. Aí o que sobra para a gurizada? 0 tráfico, a droga. 0 que é o sonho do moleque do morro? Ter um tênis de marca, ir ao shopping, mas para isso tem que ter dinheiro! Mas imagina se a gente está com casas, vida digna e emprego? Os guris vão ter o dinheirinho deles, vão poder comprar o que eles querem, vão dar continuidade nos estudos. Essas melhorias nós não queremos só para nós, só para a comunidade, a gente quer para o entorno também, porque eles convivem junto aqui. Os jovens aqui tudo jogam futebol, tanto aqui do entorno da parte de Teresópolis, da parte da Embratel, da Graciliano mesmo, tudo jogam junto com nossos meninos aqui no campo de chão batido." (Janja, liderança feminina quilombola, Quilombo Alpes, Porto Alegre, 09/05/2018).
\end{abstract}

Com as mulheres quilombolas, renasce junto à força de suas raízes a dimensão afetiva enquanto expressão coletiva, essa que refuta o caráter de propriedade. A forma mais concreta de mostrar 0 afeto como expressão coletiva das mulheres quilombolas se dá pelo não recurso à violência dos algozes; elas têm por objetivo justamente superar esses processos discriminatórios e opressivos. Reconhecem na luta política a tomada de consciência da esfera pública, essa vinculada radicalmente às demandas do quilombo, mas não apenas do "seu quilombo", e sim de todos/as.

No dizer de Beatriz Nascimento (1985, p. 44-46), "os quilombos são como sistemas sociais alternativos, [...] contra as formas de opressão. Sua mística vai alimentar o sonho de liberdade de milhares de escravos", por isso consagraram durante e posteriormente ao regime escravista uma forma de vivência e sociabilidade muito distinta da imposta pela colônia e sociedade capitalista.

Dito isso, importa destacar, ainda que de modo breve, que as revoltas dos/as africanos/as não foram de primeira instância o motivo para uma maior força punitiva do Estado imperial sobre eles/as. Evidente que, com a Revolta dos Malêsvi, intensificaram-se as formas de repressão e controle dos/as cativos/as. No entanto, o que é preciso destacar aqui é que as pessoas escravizadas tiveram tanto sua força de trabalho a serviço dos senhores de terra quanto também serviram para formular $e$ testar o sistema de justiça e penal brasileiro. Esses dois elementos indissociáveis são muito importantes no trato analítico e histórico do que entendemos por formação social, política, jurídica, econômica e socioespacial brasileira. Além de utilizar força de trabalho escravizada via mercado de pessoas e, mais tarde, na economia subterrânea do tráfico, o sistema de justiça brasileiro construiu, a partir disso, uma marca deletéria desse sistema sobre os/as africanos/as e suas gerações. Buscou-se, por meio desse sistema, incorporar aos/às negros/as a ideia de menor valor, de trabalho 
desqualificado, de sujeitos/as sob tutela do sistema criminal, justamente porque as leis de criminalização fundaram-se com o propósito central de contê-los/as e privá-los/as de quaisquer direitos.

Sem dúvida, essa foi também uma estratégia de levar corpos negros para conflitos armados; ainda que não fossem soldados preparados, eram usados como uma espécie de escudo protetor da infantaria. Por isso, a alforria e a liberdade foram concedidas após o combate, e não antes mesmo desses homens ingressarem na guerra. A cidadania só seria "dada" caso esse homem negro e escravo fizesse por merecer. No entanto, como será visto mais abaixo, tal merecimento não bastava com a ida à guerra, que nesse caso também não era sua vontade, mas do seu senhor. Ocorre que o Estado Imperial sabia que o número de negros vivos seria infinitamente menor do que o número enviado para o combate. Para Clóvis Moura (1987, p. 53-54), essa prática serviu puramente para safar os senhores do combate, visto que:

[...] os escravos passaram a ser recrutados e muitos fugiram dos seus senhores para se alistarem objetivando alcançar a liberdade que Ihes era prometida. Ele é também alforriado pelo Império e os chamados escravos da nação são incorporados às tropas brasileiras. Os senhores, por seu turno, para fugirem ao dever de se incorporarem as tropas, enviam em seu lugar escravos da sua propriedade em número de um, dois, três e até mais. Com a deserção quase total da classe senhorial dos seus deveres militares, o Exército será engrossado substancialmente por escravos negros (voluntários ou engajados compulsoriamente), capoeiras, negros forros, mulatos desocupados etc.

No entanto, mesmo com a vinda do escravo vivo da guerra, não estava garantido o direito à liberdade e à alforria, pois esse escravo, dentro do ordenamento jurídico previsto na Constituição de 1824, era uma propriedade do senhor, sendo esse um dos direitos individuais previstos no art. 179. Logo:

\footnotetext{
O direito à liberdade estava atrelado à própria concepção da propriedade, pois o Cidadão do Império detinha uma 'propriedade pessoal' do seu estado de homem livre [...] a obtenção da liberdade pelos escravos somente poderia surgir com respeito a propriedade dos senhores. (CAMPELLO, 2018, p. 60-62).
}

Resgatar os fundamentos históricos e filosóficos da formação jurídica brasileira tem por objetivo publicizar seus impactos no tempo presente, para compreendermos os limites impostos à garantia e exigibilidade de direitos aos remanescentes de quilombos sem desconsiderar a relação geracional das pretas raízes, porque há séculos esse sistema jurídico e penal dirige-se de forma específica a uma determinada população. Essa afirmativa parte do conteúdo trabalhado até aqui, somando às narrativas das mulheres que mostram como, no tempo presente, o quilombo resiste.

Isso explica os obstáculos na efetivação e positivação do art. 68 do Ato das Disposições Constitucionais Transitórias, previsto na Constituição Federal de 1988. Por meio dele, em 2004, a Fundação Palmares passou a ser responsável por emitir certidões às comunidades remanescentes de 
quilombos no Brasil. Cabe à fundação a responsabilidade de reconhecimento institucional da existência dos quilombos para que, posteriormente, o Instituto Nacional de Colonização e Reforma Agrária (Incra) possa conceder a titulação. Antes, todavia, ocorre o autorreconhecimento da população, que, segundo as lideranças, é quando tudo começa em âmbito legal.

Em 1995, sete anos após a promulgação da Constituição Federal, a Comunidade Boa Vista (PA) no Alto Trombetas, no município de Oriximiná, foi o primeiro quilombo brasileiro a ser reconhecido. Todavia, o não reconhecimento das populações remanescentes e a garantia constitucional desse direito ainda é uma realidade. Segundo a fundação Palmares, desde 1995, mais de 2800 comunidades foram reconhecidas, o que não significa que todas possuem certidão de titulação, essa que hoje cabe ao Incra sancionar.

Quanto à emissão de certidões, segundo o Relatório da Fundação Palmares (BRASIL, 2019), de 2004 até o ano passado, o órgão emitiu 2744 reconhecimentos: $61 \%$ desse total ficam na região nordeste, $16 \%$ no Sudeste, $11 \%$ no Sul, $7 \%$ no centro-oeste e 5\% no Norte. Ainda segundo 0 Relatório, "[...] em 2019, a FCP emitiu outras 30 certidões relativas a processos abertos em anos anteriores, resultando no total de 70 certidões emitidas do ano, contemplando $91 \mathrm{CRQs"}$ (BRASIL, 2019, p. 10). No entanto, no mesmo documento, é possível ver que o número de certidões "em análise acumulada", só no ano de 2019, foi de 286, enquanto, no ano anterior (2018), foi de 207.

O não acesso aos direitos precisa, portanto, ser lido numa perspectiva histórica, visto que a reparação só é possível na medida em que ela também publiciza as atrocidades, as violações e opressões de um povo na formação social e histórica brasileira. Para Janja, as formas de controle e opressão não acabaram, e sim sofreram transformações.

\footnotetext{
"Eu sempre falo que a escravidão acabou, e que a gente tem que trazer sempre à memória, resgatar algumas coisas para passar para os nossos pequenos, mas a gente ainda continua escravo da papelada. 0 nosso chicote, a nossa chibata, é a caneta, porque a gente está sempre refém da assinatura dos governos para deliberar. Então acho que a nossa maior dificuldade é essa. A gente sabe que existem os recursos, a gente sabe que a gente tem direitos, mas é uma dificuldade para tu acessar. E quando acessa, dependendo das brigas políticas e governamental, tu ficas na espera." (Janja, liderança feminina quilombola, Quilombo Alpes, Porto Alegre, 09/05/2018).
}

Esses elementos são indispensáveis na compreensão do não acesso aos direitos sociais das mulheres, homens, jovens e idosos/as quilombolas - violações que se dão desde as barreiras na formalização de uma associação até a atenção à saúde. Para as lideranças quilombolas, esses obstáculos tendem a colocar em questão a sobrevivência dos quilombos, visto que sem a intervenção do Estado social não é possível combater a ofensiva do capital. Tanto os quilombos urbanos quanto os 
rurais estão sob essa tensão, mesmo os que já possuem o título. Para Janja, as formas de geração de renda sem atuação do poder público não são suficientes.

\begin{abstract}
"Os quitutes ficam mais no entorno, é um meio de sustento e um meio de fazer a manutenção aqui da sede que dá gasto. A gente não tem ajuda de parte alguma, tanto é que esse espaço (Associação) a gente construiu com a ajuda de uma organização luterana e com doações que a gente conseguiu. E continuamos aí pleiteando... agora mesmo a gente conseguiu um recurso, mas está parado, está preso lá na Secretaria da Saúde. Esse recurso é para ser investido no posto dentro da sede, mas como o telhado estava meio danificado, a gente pediu para ser investido o primeiro recurso aqui. Também estamos querendo fazer melhorias, uma delas é fazer a biblioteca, e no espaço que o médico está atendendo uma vez por semana as pessoas, pois elas não conseguem acessar o posto, porque fica bem distante e tem dificuldade para descer. Mas esse recurso está lá parado... então a gente faz o que pode, tanto é que eu faço os almoços, coisa assim, e as trilhas para ajudar mais um pouco. É uma troca, né? É uma maneira da gente poder também preservar o espaço aqui. Quando tem as trilhas, é uma maneira que eu tenho de fazer uma caminhada e já dar uma preservada também, ver como é que está. $E$ os lucros são investidos aqui no quilombo. Agora mesmo eu estava com o piso, mas não tinha cimento cola, aí naquela na última caminhada, o dinheirinho que deu. eu juntei e já comprei cimento. Daí quando os meninos estão de folga, a mão de obra eles fazem, tem toda mão de obra aqui." (Janja, liderança feminina quilombola, Quilombo Alpes, Porto Alegre, 09/05/2018).
\end{abstract}

Como a Associação tem justamente esse caráter institucional e formal, as lideranças narram que a prioridade, em grande parte, tem sido em fundá-la e mantê-la. Sobre os desafios específicos da fundação, explicam que há todo um trabalho junto ao Movimento Negro, que em todas as falas aparece como central nessa luta política. Somado a ele, está o movimento das lideranças quilombolas de historicizar e conscientizar a população, o que, segundo elas, implica um desafio grande, tendo em vista que boa parte está em postos de trabalhos formais e informais fora do quilombo. Conforme nos narra Janja:

"A maior parte do pessoal trabalha fora. Tem todo o espaço, temos toda essa maravilha de ervas aí, mas não abastece, não é o suficiente. Então não temos empregos próprios aqui, o pessoal desce muito para trabalhar fora. A maioria em construção civil, os homens, as mulheres de doméstica. E a meninada aí estudando, a gente dando ensino para estudar, para se formar aí. Eu mexo com eles dizendo: eu preciso de um doutor, eu preciso de um advogado, eu preciso de uma professora, eu preciso! Então estamos aí incentivando sempre eles." (Janja, liderança feminina quilombola, Quilombo Alpes, Porto Alegre, 09/05/2018).

A ausência de uma geração de renda própria coloca essa tensão concreta e material em Ser quilombola, na medida em que o tempo dirigido ao quilombo e sua vivência coletiva também são capturados pelo modo de produção capitalista, o que insere essas mulheres quilombolas numa luta que é também de classe. Elas reconhecem que são trabalhadoras e que em boa parte atuam no mercado de trabalho como empregadas domésticas informais, ou seja, sem acesso ao direito trabalhista e previdenciário. Há, portanto, uma parcela que está em situação permanente de desemprego e que, 
segundo a liderança quilombola Vanda, conta com as estratégias de solidariedade dos demais quilombolas.

\begin{abstract}
"Meu marido é aposentado, a gente planta, a gente tem uma horta, a minha mãe também é aposentada. Os que não são, como os meus irmãos que moram aqui, eles fazem algum trabalho nos arredores, e eles também trabalham aqui com a gente. Aquele que tem uma renda fixa ajuda aquele que não tem, entendeu? É sempre uma troca de trabalho. $O$ objetivo mesmo é o quilombo trabalhando aqui, as pessoas, os integrantes daqui os quilombolas trabalhando aqui. Por isso, quando tem que fazer alguma no quilombo a gente não vai buscar uma pessoa de fora para pagar para fazer, então eles estão aqui e colaboram como 0 que podem. É assim é que funciona." (Vanda, liderança quilombola feminina, Quilombo Rincão dos Fernandes, Uruguaiana, 21/04/2018).
\end{abstract}

Quanto às mulheres que vivem em quilombos na zona rural do estado, há um maior número delas aposentadas, pois, segundo elas, acessaram esse direito via trabalho rural. Tal situação tem se reconfigurado, pois, aos mais jovens e com média de cinquenta anos, a informalidade e a falta de acesso ao trabalho assegurado e regulado pelo Estado têm compelido à ocupação de postos de trabalho com menor remuneração e mais precários, havendo também a impossibilidade de até mesmo acessar esse nicho.

Nota-se que a precarização no acesso ao trabalho remunerado e assegurado é posta como um dos desafios no acesso à cidadania. Sem o trabalho mediado pela ação do Estado social, as mulheres quilombolas passam a compor as estatísticas gerais sobre desemprego e informalidade, como uma expressão que se sobressai em corpos pretos, periféricos, com baixa escolarização e em situação geracional de informalidade. Tais dados, no curso da história brasileira, mostram não só um acesso seletivo à cidadania, mas o seu encurtamento. A garantia constitucional do Art. 68 ainda é um desafio para as populações remanescentes de quilombos. $O$ não reconhecimento e a violação desse direito é uma forma de perpetrar a seletividade oriunda da Constituição Imperial de 1824. A estrutura jurídica, portanto, ao longo dos séculos, tem se fundamentado nessa segregação. $E$, embora a Carta Magna ponha em xeque essa segregação, a sua exigibilidade e positivação são obstaculizadas em face da estrutura racista que ainda marca não só o sistema de direitos à cidadania, mas a sociedade brasileira.

\title{
4 CONCLUSÃO
}

Conforme vemos nas narrativas das lideranças quilombolas, as estratégias de manutenção e sobrevivência sem a atuação do Estado social não são suficientes, visto que sem o acesso assegurado ao trabalho e à renda, essas populações ficam não só desprotegidas do ponto de vista social, mas vulneráveis em face da barbárie do capital. Suas terras, sejam elas nas áreas urbanas 
ou rurais, estão constantemente sob a mira dos grandes latifundiários e do mercado imobiliário. Recai sobre as/os próprias/os sujeitas e sujeitos quilombolas a responsabilidade de gerar os cuidados de todas as ordens do quilombo e, ao mesmo tempo, lidar com essa especulação mercadológica, que tende a criar sentidos individualizantes e segregados dentro dessas comunidades.

Há, portanto, uma luta diária dessas mulheres em manter o sentido e o pertencimento de Ser quilombola para todos/as, mas especialmente para os mais jovens, que sofrem com a falta de oportunidade e perspectiva de futuridade tanto nas áreas rurais quanto urbanas. Isso se dá em decorrência da ausência estatal na garantia de direitos e acesso à cidadania. Não por acaso passado e presente para os/as quilombolas são intrínsecos. $O$ ato político de rememoração de suas vidas e histórias, além de ser uma forma concreta de manutenção da vida do próprio quilombo e de Ser quilombola, se dá também no acesso aos direitos, no reconhecimento de suas terras, de suas lutas e identidade. Com essas lideranças quilombolas, apreendemos o sentido de manter viva a memória para fazer valer o presente. A luta dos/as quilombolas, portanto, não é uma luta pelo quilombo, mas uma luta pela Terra, como bem disse Beatriz Nascimento (1985).

E, por fim, entre os achados da pesquisa, destaca-se a necessidade de tencionar a atuação, responsabilização e o compromisso constitucional do Estado junto às comunidades remanescentes de quilombos. Faz-se necessário, ainda, um movimento de desnaturalização em torno da resistência do povo quilombola em face das destituições e violações permanentes. Ao darmos esse enfoque, buscamos desnaturalizar, por exemplo, a situação de comunidades que resistem às ações violentas da polícia e do Estado "via ordem de despejo". Nessa luta diária do assegurar o território, outras demandas e acesso às demais políticas públicas são proteladas. Na medida em que o Estado não é responsabilizado por assegurar o direito à terra dessas comunidades, elas seguem sob o mando da jurisdição seletiva e historicamente racista do sistema de justiça. Resistir contra a violência estatal por um direito já instituído coloca essas populações na relação diária do medo, da insegurança e, em alguns casos, nos circuitos de criminalização. A resistência aqui precisa estar mais radicalizada às lutas históricas dos quilombos, não só de reparação, mas de uma mudança substancial no que conhecemos por direitos, cidadania e formas de acesso. Do contrário, a resistência corre o risco de vincular-se apenas à marca da falta, e não às transformações sociais mais amplas. Essa tem sido uma das lutas diárias das comunidades quilombolas, o lançar de luzes sobre necessidades e direitos que, em virtude da negação do primeiro direito - 0 direito à terra - são inviabilizados. A inviabilidade tem sido um recurso do Estado capitalista de se isentar e atribuir toda a responsabilidade que lhe cabe às comunidades, o que, na prática, tem gerado uma incansável luta pela positivação dos direitos. 


\section{REFERÊNCIAS}

ALMEIDA, Sílvio. 0 que é Racismo Estrutural? Belo Horizonte: Letramento, 2018.

BARDIN, Lawrence. Análise de Conteúdo. Edições Lisboa, 1977.

BRASIL. Fundação Cultural Palmares. Certificação Quilombola. Portal da Fundação Cultural Palmares, 2021. Disponível em: http://www.palmares.gov.br/?page_id=37551. Acesso em: 20 jun. 2021.

BRASIL. Fundação Cultural Palmares. Relatório de Gestão de 2019. Brasília, 2019. Disponível em: http://www.palmares.gov.br/?page_id=37551. Acesso em: 20 jun. 2021.

BRASIL. Decreto $n^{0} 4.887$, de 20 de novembro de 2003. Regulamenta o procedimento para identificação, reconhecimento, delimitação, demarcação e titulação das terras ocupadas por remanescentes das comunidades dos quilombos de que trata 0 art. 68 do Ato das Disposições Constitucionais Transitórias. Brasília, 2003. Disponível em:

http://www.planalto.gov.br/ccivil_03/decreto/2003/d4887.htm. Acesso em: 20 jun. 2021.

BRASIL. Constituição da República Federativa do Brasil de 1988. Brasília, 1988. Disponível em: http://www.planalto.gov.br/ccivil_03/constituicao/constituicao.htm. Acesso em: 20 jun. 2021.

BRASIL. Constituição Política do Império do Brazil (de 25 de março de 1824). Rio de Janeiro, 1824. Disponível em: http://www.planalto.gov.br/ccivil_03/Constituicao/Constituicao24.htm. Acesso em: 20 jun. 2021.

CAMPELLO, André Barreto. Manual Jurídico da escravidão: Império do Brasil. Jundiaí (SP): Paco editorial, 2018.

COMISSÃO PRÓ-ÍNDIO DE SÃO PAULO (CPISP). O Caminho da Titulação das Terras

Quilombolas. São Paulo: CPISP, 2015. Disponível em:

https://www.google.com/url?sa=t\&rct=j\&q=\&esrc=s\&source=web\&cd=\&ved=2ahUKEwiN1sDPjsDxAhVo qZUCHSIkCIYQFjAAegQIBRAD\&url=http\%3A\%2F\%2Fcpisp.org.br\%2Fwpcontent\%2Fuploads\%2F2017\%2F01\%2FCPISP_pdf_CaminhoTitulacao.pdf\&usg=AOvVaw1IBqr25NSy XAEVME4PO9K_. Acesso em: 30 jun. 2021.

COSTA, Ângela Maria Faria da. Quilombos Urbanos, Segregação Espacial e Resistência em Porto Alegre/RS: uma análise a partir dos Quilombos do Areal e da Familia Silva. 2008. 78 f. Trabalho de Conclusão de Curso (Graduação em Geografia) - Instituto de Geociências, Universidade Federal do Rio Grande do Sul (UFRGS), Porto Alegre, 2008.

FREYRE, Gilberto. Casa-grande \& senzala: formação da família brasileira sob o regime patriarcal. São Paulo: Global, 2013.

MARTINELLI, Maria Lúcia (org.). Pesquisa qualitativa: um instigante desafio. Núcleos de Pesquisa 1. São Paulo: Veras, 1999.

MOURA, Clóvis. Da Insurgência Negra ao Escravismo Tardio. Estudos Econômicos, São Paulo, v. 17, n. 9 especial, p. 37-59, 1987. 
NASCIMENTO, Beatriz. O Conceito de Quilombo e a Resistência Cultural negra. Afrodiáspora, v. 3, n. 6-7, p. 41-49, 1985.

OLIVEIRA, Fernando Bueno; D’ABADIA, Maria Idelma Vieira. Territórios quilombolas em contextos rurais e urbanos brasileiros. Élisée, v. 4, p. 257-275, 2015.

RATTS, Alex. Eu sou atlântica: sobre a trajetória de vida de Beatriz Nascimento. São Paulo: Instituto Kuanza, 2006.

REIS, João José. Rebelião Escrava no Brasil: a história do levante dos Malês em 1835. 3. ed. rev. e ampl. São Paulo: Companhia das letras, 2012.

SANTOS, Milton. O Dinheiro e o Território. GEOgraphia, n. 1, p. 7-13, 1999.

SILVA, Taís de Medeiros. Trajetórias de desterritorializações e reterritorializações: estudo de caso: comunidade quilombola da Família Fidélix - Porto Alegre/RS. 2015. 186 f. Dissertação (Mestrado em Geografia) - Programa de Pós-Graduação em Geografia, Universidade Federal do Rio Grande do Sul (UFRGS), Porto Alegre, 2015.

SOMMER, Michelle Farias. Territorialidade negra urbana: a morfologia sócio-espacial dos núcleos negros urbanos segundo a herança história comum. 2005. 224 f. Dissertação (Mestrado em Planejamento Urbano e Regional) - Programa de Pós-Graduação em Planejamento Urbano e Regional, Universidade Federal do Rio Grande do Sul (UFRGS), Porto Alegre, 2005.

\section{Notas}

1 Entidade vinculada ao Ministério da Cidadania e responsável pela emissão de certidões às comunidades quilombolas (BRASIL, 2021).

2 "[...] grupos que, em meio a um contexto urbano multicultural, fragmentado e em eterna dinâmica, demarcam sua identidade mobilizando critérios étnicos" (OLIVEIRA; D’ABADIA, 2015, p. 269).

3 Regulamenta o procedimento para identificação, reconhecimento, delimitação, demarcação e titulação das terras ocupadas por remanescentes das comunidades dos quilombos de que trata 0 art. 68 do Ato das Disposições Constitucionais Transitórias (BRASIL, 2003).

${ }^{4}$ Segundo o Onir Araújo, Presidente da Frente Quilombola do Rio Grande do Sul, há mais dois quilombos buscando o reconhecimento no município de Porto Alegre. Além do Quilombo Kedi, o Quilombo Santa Luzia e outro quilombo localizado na Lomba do Pinheiro.

5 "[...] perda de vínculos com o lugar e com as relações efetivamente nele realizadas, significando estranhamento e rompendo com a formação dos sistemas simbólicos instituídos através de práticas socioculturais responsáveis pela construção social do lugar" (SOMMER, 2005, p. 37).

${ }^{6}$ Segundo João José Reis (2012, p. 246), a Revolta dos Malês ocorreu na Bahia, em 1835, e não foi uma explosão de um ato do acaso, pelo contrário, esse levante foi planejado e gestado tempo antes de sua ação concreta, tendo como referência ações sem sucesso de revoltas escravas anteriores. Os Malês não só incorporaram as pautas de superação das relações de opressão e dominação sobre o povo africano, como também visaram a superação da cultura escravocrata. Por serem em maioria africanos e africanas de origem mulçumana, a estratégia era difundir a soberania dos povos africanos, o que gerou nesse período fortes tensões, discussões na história africana na Bahia. 